\title{
What Patients Want From Primary Care Consultations: A Discrete Choice Experi- ment to Identify Patients' Priorities
}

\author{
Sudeb Cheragbi-Sobi, BSc ${ }^{1}$ \\ Arne Risa Hole, $P b D^{2}$ \\ Nicola Mead, PbD \\ Ruth McDonald, $P b D^{1}$ \\ Diane Whalley, MSc ${ }^{1}$ \\ Peter Bower, $P b D^{1}$ \\ Martin Roland, $D M^{1}$ \\ 'National Primary Care Research and \\ Development Centre (NPCRDC), Univer- \\ sity of Manchester, Manchester, United \\ Kingdom \\ ${ }^{2}$ National Primary Care Research and \\ Development Centre (NPCRDC), Centre \\ for Health Economics, University of York, \\ York, United Kingdom
}

Conflicts of interest: none reported

\section{CORRESPONDING AUTHOR}

Peter Bower, PhD

National Primary Care Research

and Development Centre

University of Manchester

Manchester M13 9PL, United Kingdom

peter.bower@manchester.ac.uk

\begin{abstract}
PURPOSE The consultation is fundamental to the delivery of primary care, but different ways of organizing consultations may lead to different patient experiences in terms of access, continuity, technical quality of care, and communication. Patients' priorities for these different issues need to be understood, but the optimal methods for assessing priorities are unclear. This study used a discrete choice experiment to assess patients' priorities.
\end{abstract}

METHODS We surveyed patients from 6 family practices in England. The patients chose between primary care consultations differing in attributes such as ease of access (wait for an appointment), choice (flexibility of appointment times), continuity (physician's knowledge of the patient), technical quality (thoroughness of physical examination), and multiple aspects of patient-centered care (interest in patient's ideas, inquiry about patient's social and emotional well-being, and involvement of patient in decision making). We used probit models to assess the relative priority patients placed on different attributes and to estimate how much they were willing to pay for them.

RESULTS Analyses were based on responses from 1,193 patients (a 53\% response rate). Overall, patients were willing to pay the most for a thorough physical examination (\$40.87). The next most valued attributes of care were seeing a physician who knew them well (\$12.18), seeing a physician with a friendly manner $(\$ 8.50)$, having a reduction in waiting time of 1 day (\$7.22), and having flexibility of appointment times (\$6.71). Patients placed similar value on the different aspects of patient-centered care (\$12.06-\$14.82). Responses were influenced by the scenario in which the decision was made (minor physical problem vs urgent physical problem vs ambiguous physical or psychological problem) and by patients' demographic characteristics.

CONCLUSIONS Although patient-centered care is important to patients, they may place higher priority on the technical quality of care and continuity of care. Discrete choice experiments may be a useful method for assessing patients' priorities in health care.

Ann Fam Med 2008;6:107-115. DOI: 10.1370/afm.816.

\section{INTRODUCTION}

\} ealth care professionals are encouraged to deliver patient-centered services. In health policy terms, this refers to services "closely congruent with, and responsive to patients' wants, needs and preferences."1

\section{Patient-Centered Services}

In primary care, the physician-patient consultation is the fundamental platform for service delivery. Making consultations more congruent with patients' preferences can be achieved through a number of mechanisms, such as competition among health care professionals and measurement 
and feedback of patients' satisfaction. Achieving congruence is complicated, however, because of the many attributes of primary care consultations that are important to patients. For example, patients want rapid access to professionals and high-quality technical and interpersonal care. ${ }^{2-4}$ Meeting expectations concerning a range of attributes may be difficult within the constraints of limited budgets, however. For example, relational continuity (ie, the ability "to provide 1 or more named professionals with whom the patient can develop a therapeutic and interpersonal relationship ${ }^{\prime \prime}$ ) may be jeopardized if services prioritize rapid access. ${ }^{6}$

The range of attributes that are important to patients is relatively well known ${ }^{2}$; however, designing services that are sensitive to patients' preferences in the context of limited resources may require patients to choose between attributes. ${ }^{7}$ This reality has led to interest in methods of assessing priorities. ${ }^{8}$ One promising method is the discrete choice experiment, used in psychology, marketing, and economics. Discrete choice experiments are based on the assumption that services (such as consultations) can be described by their attributes, and the value of a service depends on the nature and level of these attributes. Individuals are presented with alternative hypothetical services consisting of a number of attributes with different levels, and are asked to choose between them. Discrete choice experiments can ascertain individuals' priorities by estimating the relative importance of different attributes to them. ${ }^{9}$

\section{Patient-Centered Care}

Two key dimensions of the quality of primary care are technical care (ie, the quality of clinical care) and interpersonal care (ie, the quality of communication between professional and patient). ${ }^{3}$ Health care professionals' communication skills are often described under the broad label of patient-centered care, which encompasses a number of communication issues, including (1) giving attention to biological, psychological, and social aspects of health (biopsychosocial perspective), (2) exploring the personal meaning of illness (patient as person), (3) increasing the involvement of patients in their care (sharing power and responsibility), and (4) giving greater priority to the personal relationship between physician and patient (attending to the therapeutic alliance). ${ }^{10}$

Although the evidence linking patient-centered care to improved patient outcomes is somewhat ambiguous, ${ }^{11-13}$ considerable scientific, ethical, and professional momentum supports the adoption of a patient-centered care model. ${ }^{14}$

Discrete choice studies in primary care show that communication is highly valued..$^{15-18} \mathrm{~A}$ small preconsultation survey ( $\mathrm{N}=101$ patients) found that "being able to talk to the doctor" was more important than other attributes such as waiting times, involvement in decision making, and the type of explanation received, ${ }_{1}{ }^{17}$ and this finding was replicated in a larger postal survey ( $\mathrm{N}=734$ patients). ${ }^{18}$ Similar results have been reported in studies of care outside of routine hours. ${ }^{16,19}$

The attributes used to test the priorities placed on patient-centered care in published studies have not accurately reflected the complexity of the patientcentered care concept, however. Only 1 study has tested patients' preferences for a specific aspect of patient-centered care, namely, shared decision making. ${ }^{20}$ That study found that although patients with chronic disease valued shared decision making, it was less of a priority than whether the physician seemed to listen.

The high priority patients place on communication issues nonetheless requires critical examination. Many studies do not include a measure of technical care, and patients may assume that technical care is of high quality if there is no suggestion to the contrary. ${ }^{21}$ A study from the United States that asked patients to choose between physician report cards differing on interpersonal and technical care found that more patients chose the physician with high technical care scores ${ }^{7}$; however, the methods used in this study were unable to estimate the relative importance of different attributes. Another discrete choice study also reported that technical care was the most important factor in determining patient choice of a physician (accounting for $27 \%$ of the variance), compared with waiting time $(15 \%)$, billing problems $(20 \%)$, time to get a referral (18\%), and who made health care decisions (20\%). ${ }^{22}$

If service delivery is to be acceptable to patients, policy makers need to understand patients' priorities. The published literature does not clearly define the relative importance patients place on attributes such as technical and interpersonal care. In this study, we used a discrete choice experiment to comprehensively assess patients' priorities for a range of attributes of primary care consultations, including access, technical care, continuity, and multiple attributes relevant to patientcentered care.

\section{METHODS}

A discrete choice experiment can be described in terms of a number of key stages: (1) selection of attributes, levels, and scenarios, (2) experimental design and construction of choice sets, (3) measurement of preferences, (4) estimation procedure, and (5) tests of the validity of responses. ${ }^{23}$ Each stage is described below.

\section{Selection of Attributes, Levels, and Scenarios} We developed candidate attributes and levels from a "map" of concepts relating to primary care developed 
through a theoretical and empirical review. ${ }^{24}$ We then used qualitative "think aloud" techniques ${ }^{25}$ to test patients' comprehension of these candidate attributes ${ }^{26}$ and conducted a quantitative pilot study among 30 patients to test the questionnaire's properties.

On the basis of the final list of quality concepts, attributes, and levels, we generated 2 discrete choice questionnaires: a generic version (including a wide range of attributes of relevance to primary care) and a version focused on patient-centered care (Table 1). Our decision to use 2 questionnaires was made on both theoretical and practical grounds. As highlighted earlier, primary care quality has multiple dimensions, and we wanted to provide a comprehensive assessment of patients' priorities; however, we also were specifically interested in the issue of patient-centeredness, itself a multidimensional concept. ${ }^{10}$ Our desire to capture both the breadth of quality and the depth of issues relating to patient-centeredness led to a list of dimensions that would have been prohibitive for a respondent to complete. We therefore created 2 questionnaires. Some items were common to both (Table 1), to allow comparison across the 2 questionnaires.

To obtain an easily interpretable metric for assessing priorities and to further facilitate comparisons of priorities across the 2 different questionnaires, we used a cost attribute to assess how much patients were willing to pay for each attribute. Patients do not pay for services at the point of delivery in the United Kingdom, and we informed patients that the cost attribute was used simply to assess perceived value.

We created 3 scenarios to examine the effect of context on decision making: a minor physical problem scenario, an urgent physical problem scenario, and an ambiguous physical or psychological problem scenario (Table 2). These scenarios differed in terms of perceived urgency and the likelihood that psychological factors were involved.

\section{Experimental Design and Construction of Choice Sets}

Both the generic and the patient-centered care questionnaires included two 4-level attributes and four 2-level attributes (Table 1), giving the full factorial design 256 possible combinations of levels. To provide a manageable task for respondents, we used the Doptimality criterion to maximize the efficiency of the design. ${ }^{27,28}$ Sixteen choice sets with 2 alternatives were constructed using the CHOICEFF SAS macro (SAS Institute, Cary, North Carolina). ${ }^{29}$ To make the questionnaire more manageable, we randomly blocked 16 choice sets into 2 sets of 8 choices.

\section{Measurement of Preferences}

We presented each respondent with either the generic or the patient-centered care questionnaire, with 2

\begin{tabular}{|c|c|c|}
\hline Quality Concept & Attribute & Levels \\
\hline \multicolumn{3}{|l|}{ Generic questionnaire } \\
\hline Access & Number of days wait for an appointment ${ }^{\mathrm{a}}$ & Same day, next day, 2 days, 5 days \\
\hline Cost & Cost of appointment to patient ${ }^{\mathrm{a}}$ & $€ 0, € 8, € 18, € 28(\$ 0, \$ 16.27, \$ 36.60, \$ 56.93)$ \\
\hline Choice & Flexibility of appointment times & $\begin{array}{l}\text { One appointment offered } \\
\text { Choice of appointment times offered }\end{array}$ \\
\hline Interpersonal care & Physician's interpersonal manner & $\begin{array}{l}\text { Warm and friendly } \\
\text { Formal and businesslike }\end{array}$ \\
\hline Relational continuity & Physician's knowledge of the patient ${ }^{\mathrm{a}}$ & $\begin{array}{l}\text { The doctor has access to your medical notes and knows you well } \\
\text { The doctor has access to your medical notes but does not know you }\end{array}$ \\
\hline Technical care & Thoroughness of physical examination & $\begin{array}{l}\text { The doctor gives you a thorough examination } \\
\text { The doctor's examination is not very thorough }\end{array}$ \\
\hline \multicolumn{3}{|c|}{ Patient-centered care questionnaire } \\
\hline Access & Number of days' wait for an appointment ${ }^{\mathrm{a}}$ & Same day, next day, 2 days, 5 days \\
\hline Cost & Cost of appointment to patient ${ }^{a}$ & $€ 0, £ 8, £ 18, £ 28(\$ 0, \$ 16.27, \$ 36.60, \$ 56.93)$ \\
\hline Relational continuity & Physician's knowledge of the patient ${ }^{\mathrm{a}}$ & $\begin{array}{l}\text { The doctor has access to your medical notes and knows you well } \\
\text { The doctor has access to your medical notes but does not know you }\end{array}$ \\
\hline Patient-centered care & Patient perspective & $\begin{array}{l}\text { The doctor is interested in your own ideas about what is wrong } \\
\text { The doctor is not interested in your own ideas about what is wrong }\end{array}$ \\
\hline Patient-centered care & Biopsychosocial perspective & $\begin{array}{l}\text { The doctor asks about your social and emotional well-being as well as } \\
\text { physical symptoms } \\
\text { The doctor asks about your physical symptoms only }\end{array}$ \\
\hline Patient-centered care & Shared decision making & $\begin{array}{l}\text { The doctor involves you in decisions about treatment } \\
\text { The doctor does not involve you in decisions about treatment }\end{array}$ \\
\hline
\end{tabular}


sets of 8 choices relating to 2 of 3 scenarios. One additional choice set in each scenario repeated the first choice set; this additional set was used to assess respondents' consistency only and was excluded from the main analysis. The order of the choice sets was reversed in one-half of the questionnaires to reduce ordering effects. An example of the decision-making task, the attributes, and the scenarios presented to respondents is shown in Figure 1. Each patient was asked to complete 18 such decision-making tasks (16

\begin{tabular}{|ll|}
\hline Table 2. Scenarios \\
\hline $\begin{array}{l}\text { Scenario } \\
\text { Minor physical } \\
\text { problem }\end{array}$ & $\begin{array}{l}\text { Description } \\
\text { some itchy, flaky patches on your hands. Occa- } \\
\text { sonally they become quite red and sore. The } \\
\text { problem does not appear to be spreading but } \\
\text { has not responded to ointment recommended } \\
\text { by the chemist. You decide to seek a medical } \\
\text { opinion. }\end{array}$ \\
$\begin{array}{l}\text { Irgent physical } \\
\text { problem }\end{array}$ & $\begin{array}{l}\text { want you to imagine that you have a heavy } \\
\text { cough and cold. Over the past } 2 \text { days you } \\
\text { of your chest. It is very sharp and worse if you } \\
\text { cough or take a deep breath in. You decide to } \\
\text { seek a medical opinion. }\end{array}$ \\
$\begin{array}{l}\text { Ambiguous } \\
\text { physical or } \\
\text { psychologi- } \\
\text { cal problem }\end{array}$ & $\begin{array}{l}\text { want you to imagine that you are in your } \\
\text { current state of health but over the last few } \\
\text { months you have been feeling tired and irrita- } \\
\text { ble and have had difficulty sleeping. You have } \\
\text { tried several things yourself to remedy this but } \\
\text { are not feeling any better. You decide to seek } \\
\text { a medical opinion. }\end{array}$ \\
\hline
\end{tabular}

different tasks plus repetition of 2 of the 16 to assess consistency of response).

This study was approved by the local research ethics committee. We approached practices in Greater Manchester, England, to participate. Six volunteer practices were selected and stratified by practice size and a composite measure of various deprivation indices. Patients were randomly selected from practice lists and stratified by sex and 3 age bands (18-35, 36-59, and $\geq 60$ years). We mailed each patient 1 of the 24 different versions of the questionnaire with an information sheet, and mailed written reminders 4 and 8 weeks later.

There are no formal sample size calculations for discrete choice experiments, but a conventional heuristic suggests use of 50 patients per subgroup in the analysis. We assumed 6 subgroups. Because each patient completed 2 of 3 scenarios, we needed 450 responses per questionnaire to ensure that 300 responses were available per scenario. On the assumption of a $40 \%$ response rate, we sent each questionnaire to 1,125 patients, for a total of 2,250 patients.

\section{Estimation Procedure}

We analyzed data using probit models, a conventional approach in the analysis of discrete choice experiments. We also calculated random effects probit models, which provide more accurate estimates of coefficients when responses from the same patients are correlated. Confidence intervals for willingness to pay

Figure 1. Structure of the discrete choice questionnaire.

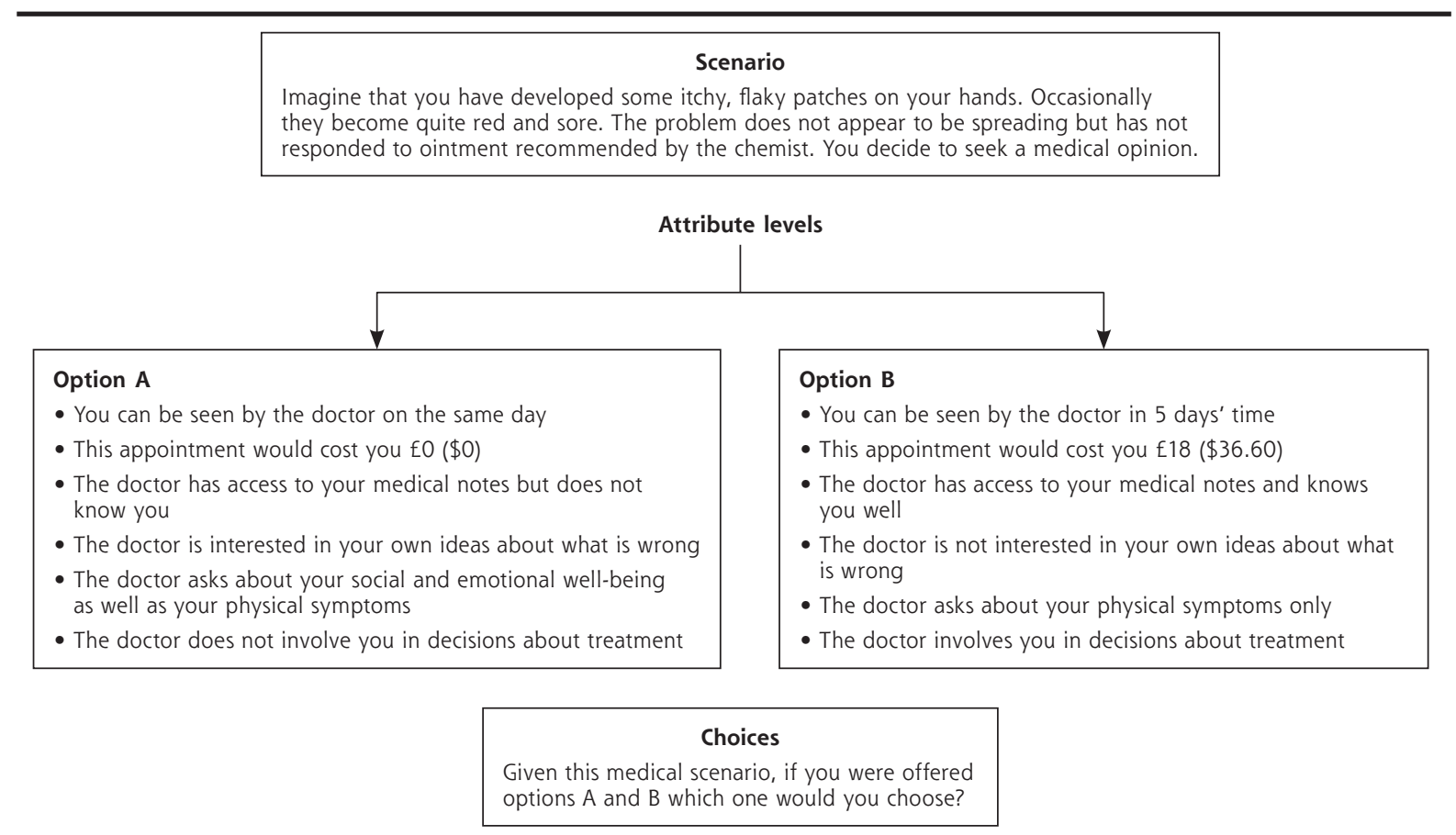


were estimated using the method of Fieller. ${ }^{30}$ We conducted an analysis weighted for nonresponse. We also carried out preplanned assessments of statistical interactions between attributes and demographic characteristics to examine whether particular characteristics were associated with patients' priorities. All statistical analyses were performed using Stata 9 (StataCorp, College Station, Texas).

\section{Tests of the Validity of Responses}

Discrete choice experiments assume that individuals give rational responses (ie, consider all available information and make decisions on the basis of maximizing utility) and are willing to trade between choices. ${ }^{23}$ We tested these assumptions using (1) tests of consistency, to assess whether respondents always chose the same alternatives when presented with identical choice sets, and (2) tests of lexicographic preferences, to assess whether respondents always chose the alternative with the best level of a particular "favored" attribute, suggesting an unwillingness to trade between attributes. ${ }^{31}$

\section{RESULTS}

\section{Practice and Patient Characteristics}

The 6 practices participating in the study ranged in size from 1 to 8 general practitioners. Of the 25 general practitioners, 12 (48\%) were male, 13 (52\%) were younger than 45 years of age, and 16 (64\%) had obtained their medical degree in the United Kingdom.

The overall response rate to the questionnaire among patients was 53\% (generic version, $55.8 \%$; patient-centered care version, 50.2\%). Response varied with age and sex: response rates were $32.8 \%, 45.9 \%$, and $72.8 \%$ among men aged 18 to 35,36 to 59 , and 60 years or older, respectively, and $40.3 \%, 64.3 \%$, and $62.1 \%$ among women in these age groups. There was a small amount of additional missing data for some characteristics (eg, age, income, and long-term illness status). The demographic characteristics of the 1,193 respondents are shown in Table 3.

\section{Consistency and Willingness to Trade}

On the generic questionnaire, $8.1 \%$ of respondents failed the consistency test for 1 scenario, and $0.6 \%$ failed the test for both scenarios in the questionnaire. The respective rates for the patient-centered care questionnaire were $13.3 \%$ and $1.8 \%$. Patients who failed consistency tests were included in the main analysis, although their responses to the extra choice set included as the consistency test were excluded.
Table 3. Demographic Characteristics of the Patient Sample

\begin{tabular}{|c|c|c|}
\hline Characteristic & $\begin{array}{c}\text { Generic } \\
\text { Questionnaire } \\
(n=628)^{a}\end{array}$ & $\begin{array}{l}\text { Patient-Centered } \\
\text { Care Questionnaire } \\
(\mathrm{n}=565)^{\mathrm{a}}\end{array}$ \\
\hline Female, \% & 55.0 & 52.4 \\
\hline Age, mean (SD), years & $52.5(17.9)$ & $53.0(18.3)$ \\
\hline \multicolumn{3}{|l|}{$\begin{array}{l}\text { Number of dependent children } \\
\text { in household, \% }\end{array}$} \\
\hline 0 & 70.1 & 71.7 \\
\hline $1-2$ & 26.4 & 23.6 \\
\hline$\geq 3$ & 3.5 & 4.7 \\
\hline \multicolumn{3}{|l|}{ Household income, \% } \\
\hline$<€ 20,000$ & 49.1 & 45.9 \\
\hline$€ 20,000-€ 39,999$ & 35.1 & 34.4 \\
\hline$€ 40,000-£ 59,999$ & 11.5 & 14.7 \\
\hline$\geq € 60,000$ & 4.3 & 4.9 \\
\hline Have a long-term illness, \% & 46.1 & 45.7 \\
\hline White, \% & 94.7 & 95.7 \\
\hline $\begin{array}{l}\text { Overall health is "good" or } \\
\text { "very good," \% }\end{array}$ & 59.5 & 63.3 \\
\hline \multicolumn{3}{|l|}{$\begin{array}{l}\text { Number of visits to physician } \\
\text { in past } 12 \text { months, \% }\end{array}$} \\
\hline$\leq 2$ & 44.4 & 50.5 \\
\hline $3-4$ & 26.7 & 24.3 \\
\hline$\geq 5$ & 28.9 & 25.2 \\
\hline $\begin{array}{l}\text { Own/have a mortgage on their } \\
\text { residence, \% }\end{array}$ & 76.2 & 76.7 \\
\hline
\end{tabular}

There was evidence that respondents were unwilling to trade between attributes on $26.6 \%$ of the generic questionnaires and $20.2 \%$ of the patient-centered care questionnaires. Attributes commonly associated with an unwillingness to trade were cost, waiting time, and thoroughness of examination.

\section{Generic Questionnaire}

Relative Importance Placed on Attributes

All attributes had coefficients that were significantly different from 0 (indicating that the attributes influenced decision making) and of the expected sign (Table 4).

The willingness to pay estimates are the most easily interpretable measure of the relative importance placed on attributes and are shown in Table 5. As examples, a willingness to pay for waiting time of $-\$ 7.22$ indicates that patients are on average willing to pay $\$ 7.22$ for a 1 -day reduction in waiting time, and a willingness to pay for seeing a physician who knows the patient well of $\$ 12.18$ indicates that patients are on average willing to pay $\$ 12.81$ to see such a physician.

Thoroughness of physical examination was the most important attribute, followed by a physician who knew the patient well, a physician whose manner was warm and friendly, a reduction in waiting time of 1 


\begin{tabular}{|c|c|c|c|c|c|c|c|c|}
\hline \multirow{2}{*}{$\begin{array}{l}\text { Attribute or Variable } \\
\text { Generic questionnaire }\end{array}$} & \multicolumn{2}{|c|}{ All Scenarios } & \multicolumn{2}{|c|}{$\begin{array}{l}\text { Ambiguous } \\
\text { Physical/Psycho- } \\
\text { logical Scenario }\end{array}$} & \multicolumn{2}{|c|}{$\begin{array}{l}\text { Minor Physical } \\
\text { Scenario }\end{array}$} & \multicolumn{2}{|c|}{$\begin{array}{l}\text { Urgent Physical } \\
\text { Scenario }\end{array}$} \\
\hline & & & & & & & & \\
\hline Attribute & Coefficient & $t$ & Coefficient & $t$ & Coefficient & $t$ & Coefficient & $t$ \\
\hline Waiting time, days & $-0.114^{a}$ & -21.80 & $-0.053^{a}$ & -5.81 & $-0.074^{a}$ & -7.72 & $-0.210^{\mathrm{a}}$ & -21.82 \\
\hline Cost, $\mathrm{e}$ & $-0.032^{\mathrm{a}}$ & -40.22 & $-0.032^{\mathrm{a}}$ & -23.12 & $-0.044^{a}$ & -29.79 & $-0.023^{a}$ & -16.58 \\
\hline Doctor knows you well & $0.192^{\mathrm{a}}$ & 12.23 & $0.302^{\mathrm{a}}$ & 10.62 & $0.210^{\mathrm{a}}$ & 7.24 & $0.130^{\mathrm{a}}$ & 4.75 \\
\hline You get a choice of appointment times & $0.105^{\mathrm{a}}$ & 6.73 & 0.031 & 1.11 & $0.120^{\mathrm{a}}$ & 4.09 & $0.137^{\mathrm{a}}$ & 5.03 \\
\hline Doctor is warm and friendly & $0.134^{a}$ & 8.55 & $0.145^{\mathrm{a}}$ & 5.29 & $0.187^{a}$ & 6.42 & $0.070^{\mathrm{b}}$ & 2.59 \\
\hline $\begin{array}{l}\text { Doctor gives you a thorough physical } \\
\text { examination }\end{array}$ & $0.643^{a}$ & 39.28 & $0.756^{\mathrm{a}}$ & 25.50 & $0.599^{a}$ & 19.50 & $0.679^{a}$ & 23.40 \\
\hline Constant & -0.004 & -0.20 & -0.004 & -0.12 & -0.023 & -0.70 & 0.020 & 0.62 \\
\hline Variable & \multicolumn{2}{|c|}{ Value } & \multicolumn{2}{|c|}{ Value } & \multicolumn{2}{|c|}{ Value } & \multicolumn{2}{|c|}{ Value } \\
\hline Number of responses & \multicolumn{2}{|c|}{9,953} & \multicolumn{2}{|c|}{3,343} & \multicolumn{2}{|c|}{3,243} & \multicolumn{2}{|c|}{3,367} \\
\hline Number of respondents & \multicolumn{2}{|c|}{628} & \multicolumn{2}{|c|}{421} & \multicolumn{2}{|c|}{409} & \multicolumn{2}{|c|}{425} \\
\hline$\rho^{2}$ & \multicolumn{2}{|c|}{0.303} & \multicolumn{2}{|c|}{0.326} & \multicolumn{2}{|c|}{0.374} & \multicolumn{2}{|c|}{0.321} \\
\hline \multicolumn{9}{|l|}{ Patient-centered care questionnaire } \\
\hline Attribute & Coefficient & $t$ & Coefficient & $t$ & Coefficient & $t$ & Coefficient & $t$ \\
\hline Waiting time, days & $-0.119^{a}$ & -22.08 & $-0.055^{\mathrm{a}}$ & -5.65 & $-0.069^{a}$ & -7.30 & $-0.229^{a}$ & -23.04 \\
\hline Cost, $\mathrm{E}$ & $-0.035^{\mathrm{a}}$ & -43.14 & $-0.036^{a}$ & -25.48 & $-0.043^{a}$ & -29.34 & $-0.029^{a}$ & -20.00 \\
\hline Doctor knows you well & $0.305^{\mathrm{a}}$ & 18.70 & $0.317^{\mathrm{a}}$ & 10.88 & $0.359^{a}$ & 12.03 & $0.301^{\mathrm{a}}$ & 10.39 \\
\hline Doctor is interested in your ideas & $0.254^{\mathrm{a}}$ & 15.87 & $0.292^{\mathrm{a}}$ & 10.26 & $0.305^{\mathrm{a}}$ & 10.50 & $0.225^{\mathrm{a}}$ & 7.86 \\
\hline $\begin{array}{l}\text { Doctor asks about your social and } \\
\text { emotional well-being }\end{array}$ & $0.216^{a}$ & 13.01 & $0.420^{\mathrm{a}}$ & 13.91 & $0.195^{a}$ & 6.53 & $0.075^{b}$ & 2.59 \\
\hline Doctor involves you in decision making & $0.207^{a}$ & 13.06 & $0.273^{\mathrm{a}}$ & 9.86 & $0.225^{\mathrm{a}}$ & 7.92 & $0.156^{\mathrm{a}}$ & 5.44 \\
\hline Constant & 0.002 & 0.12 & -0.004 & -0.11 & 0.006 & 0.16 & 0.042 & 1.25 \\
\hline Variable & \multicolumn{2}{|c|}{ Value } & \multicolumn{2}{|c|}{ Value } & \multicolumn{2}{|c|}{ Value } & \multicolumn{2}{|c|}{ Value } \\
\hline Number of responses & \multicolumn{2}{|c|}{9,009} & \multicolumn{2}{|c|}{2,966} & \multicolumn{2}{|c|}{3,036} & \multicolumn{2}{|c|}{3,007} \\
\hline Number of respondents & & & & & & & 37 & \\
\hline$\rho^{2}$ & & & & & 0. & & 0.3 & \\
\hline $\begin{array}{l}\text { a } P<.001 \\
{ }^{\text {b }} P<.05\end{array}$ & & & & & & & & \\
\hline $\begin{array}{l}\text { Note: } \rho^{2} \text { is a measure of goodness of fit of the } d \\
\text { the log-likelihood of a constant-only model. }\end{array}$ & te choice $n$ & It is giv & $1-\mathrm{LL}(\hat{\mathrm{\beta}}) / \mathrm{LL}$ & here L & the log-lik & of th & rted model & $\mathrm{LL}(0)$ is \\
\hline
\end{tabular}

day, and flexibility of appointment times. The estimates of the random effects probit model (Supplemental

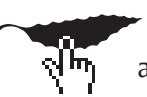
Appendix 1, available online-only at http://www. annfammed.org/cgi/content/full/6/2/107/DC1) were very similar to the estimates of the probit models in all cases.

\section{Variation in the Importance of Attributes} Across Scenarios

Across scenarios, patients were willing to pay the most for a short waiting time in the urgent physical scenario, whereas they were willing to pay the most to see a physician who knew them well in the ambiguous physical/psychological scenario (Table 5). Choice of appointment was not a significant contributor to decisions in the ambiguous physical/psychological scenario, but was more highly valued in the urgent physical scenario. A thorough examination was always the most important attribute relative to others regardless of the scenario, but its value was greatest in the urgent physical scenario and least in the minor physical scenario.

\section{Patient-Centered Care Questionnaire}

Relative Importance Placed on Attributes The coefficients and willingness to pay estimates for the patient-centered care questionnaire are shown in Tables 4 and 5, respectively. Seeing a physician who knew the patient well was most important, followed by seeing a physician who was interested in the patient's ideas, who asked about social and emotional issues, and who involved them in decisions, and having to wait 1 less day to be seen (Table 5). There was less variation in estimates of how much patients were willing to pay in the patient-centered care questionnaire compared with the generic questionnaire. The estimates of the random effects probit model (Supple- 
Table 5. Willingness to Pay Estimates Derived From Discrete Choice Models

\begin{tabular}{|c|c|c|c|c|}
\hline \multirow[b]{2}{*}{ Attribute } & \multicolumn{4}{|c|}{ Willingness to Pay, \$ $(95 \% \mathrm{Cl})$} \\
\hline & All Scenarios & $\begin{array}{c}\text { Ambiguous Physicall } \\
\text { Psychological } \\
\text { Scenario }\end{array}$ & $\begin{array}{l}\text { Minor Physical } \\
\text { Scenario }\end{array}$ & $\begin{array}{l}\text { Urgent Physical } \\
\text { Scenario }\end{array}$ \\
\hline \multicolumn{5}{|l|}{ Generic questionnaire } \\
\hline Waiting time, days & $-7.22(-7.89$ to -6.61$)$ & $-3.35(-4.49$ to -2.24$)$ & $-3.35(-4.19$ to -2.54$)$ & $-18.48(-20.96$ to -16.39$)$ \\
\hline Doctor knows you well & 12.18 (10.15 to 14.29$)$ & 19.11 (15.39 to 23.10$)$ & $9.60(6.95$ to 12.34$)$ & 11.47 (6.59 to 16.79$)$ \\
\hline $\begin{array}{l}\text { You get a choice of appointment } \\
\text { times }\end{array}$ & 6.71 (4.72 to 8.72$)$ & $1.99(-1.50$ to 5.59$)$ & 5.49 (2.85 to 8.19$)$ & 12.04 (7.20 to 17.32$)$ \\
\hline Doctor is warm and friendly & 8.50 (6.55 to 10.49$)$ & $9.17(5.75$ to 12.71$)$ & 8.58 (5.98 to 11.22$)$ & $6.14(1.50$ to 10.88$)$ \\
\hline $\begin{array}{l}\text { Doctor gives you a thorough } \\
\text { physical examination }\end{array}$ & 40.87 (38.43 to 43.45$)$ & $47.88(43.39$ to 52.88$)$ & $27.39(24.62$ to 30.29$)$ & $59.76(52.62$ to 68.38$)$ \\
\hline \multicolumn{5}{|c|}{ Patient-centered care questionnaire } \\
\hline Waiting time, days & $-6.93(-7.54$ to -6.34$)$ & $-3.07(-4.11$ to -2.03$)$ & $-3.25(-4.09$ to -2.40$)$ & $-16.16(-17.99$ to -14.58$)$ \\
\hline Doctor knows you well & $17.77(15.82$ to 19.80$)$ & 17.81 (14.54 to 21.23$)$ & $16.86(14.07$ to 19.74$)$ & $21.21(16.83$ to 26.00$)$ \\
\hline Doctor is interested in your ideas & $14.82(12.93$ to 16.77$)$ & 16.35 (13.13 to 19.76$)$ & 14.31 (11.59 to 17.14$)$ & 15.86 (11.81 to 20.15$)$ \\
\hline $\begin{array}{l}\text { Doctor asks about your social } \\
\text { and emotional well-being }\end{array}$ & 12.61 (10.69 to 14.54$)$ & 23.54 (20.19 to 27.08$)$ & 9.17 (6.42 to 11.93$)$ & $5.33(1.30$ to 9.37$)$ \\
\hline $\begin{array}{l}\text { Doctor involves you in decision } \\
\text { making }\end{array}$ & 12.06 (10.19 to 13.99$)$ & $15.31(12.12$ to 18.68$)$ & 10.55 (7.87 to 13.30$)$ & $10.98(6.97$ to 15.21$)$ \\
\hline
\end{tabular}

mental Appendix 1) were again very similar to the estimates of the probit model in all cases.

Variation in the Importance of Attributes Across Scenarios

Across scenarios, a short waiting time was more important in the urgent physical scenario (Table 5). Seeing a physician who asked about social and emotional issues was least highly valued in this scenario but valued most in the ambiguous physical/psychological scenario. Seeing a physician who knew the patient well was more important to patients in the urgent physical scenario, whereas shared decision making was more so in the ambiguous physical/psychological scenario.

\section{Influence of Demographic Characteristics}

Age, household income, and having a long-term illness influenced patients' priorities, on both the generic questionnaire and the patient-centered care questionnaire. Detailed results are presented in Supplemental Appendix 2 (available online-only at http://www. annfammed.org/cgi/content/full/6/2/107/DC1).

\section{Nonresponse Bias}

The analyses weighted for nonresponse showed coefficients that were generally similar to those of the unweighted analyses, although the precise order of importance of attributes changed in a minority of cases (Supplemental Appendix 3, avail-

able online-only at http://www.annfammed. org/cgi/content/full/6/2/107/DC1).

\section{DISCUSSION}

In terms of generic attributes of primary care consultations, patients valued thoroughness of physical examination most highly, followed by seeing a physician who knew them well, seeing a physician with a friendly manner, having a reduction in waiting time of 1 day, and having flexibility in selecting appointment times. Patients placed similar value on different attributes of patient-centered care, although the highest value was placed on seeing a physician who knew them well, followed by seeing a physician who was interested in their ideas, one who asked about social and emotional issues, and one who involved them in decisions.

\section{Methodologic Issues}

Our results are based on responses from primary care patients in the United Kingdom, and they may not be generalizable to patients in different settings, where priorities for certain aspects of care (such as waiting times) might differ considerably. Preferences for aspects of patient-centered care might be expected to be more stable across settings, given the consistent experience of the physician-patient relationship however, our findings clearly require replication in other contexts. The inclusion of the cost attribute has considerable advantages in terms of interpreting the results, but it must be reiterated that patients in the United Kingdom do not routinely pay for health care at the point of delivery, and therefore the interpretive advantages may be offset by some loss of validity.

Previous discrete choice studies in the primary care 
setting have had response rates of $18 \%$ to $76 \% .{ }^{16-19}$ Our response rate of $53 \%$ was reasonable given a complex questionnaire and an unselected group of patients. The only available data on nonrespondents were their age and sex, and these data showed some bias in that older patients and women were more likely to respond. A more comprehensive evaluation of nonresponse bias in terms of variables such as patients' attitudes is not possible.

Tests showed patients were reasonably consistent in their responses, with a consistency level equivalent to those in studies of patient valuation conducted in the United States. ${ }^{7,32}$ Other tests indicated that about one-quarter of patients were unwilling to trade between attributes, which might call the validity of the discrete choice methodology into question and make interpretation of the coefficients difficult; however, tests of trading behavior have limitations. For example, respondents may not be willing to trade over the levels of attributes presented, but may be willing to do so if offered different levels. ${ }^{33}$ Published discrete choice experiments often do not report comparative data on trading, although those that do report equivalent or higher levels of unwillingness to trade. ${ }^{19,32}$ Clearly, this issue requires further methodologic research.

The lower priority patients placed on communication and patient-centered care in our study compared with that in previous studies may reflect the fact that previous studies all used attribute levels of "the doctor seemed to listen" and "the doctor did not seem to listen," whereas our descriptors contrasted "warm and friendly" with "formal and businesslike." Our intention was to draw a more subtle and realistic distinction between physicians than was made in the earlier studies. Although it is not certain which wording is more valid, the wording we used did have the advantage of extensive qualitative testing. ${ }^{26,34}$ Our study showed that the value patients placed on the 3 patient-centered care attributes was similar, although the importance of a physician who asks about social and emotional issues seemed to be more scenario dependent.

\section{Relevance of the Findings for Health Policy} Overall, our results provide health policy makers with a comprehensive assessment of patients' priorities together with a useful financial measure of their relative value. These results can inform discussions about issues such as pay for performance and the balance to be struck between incentives for technical and nontechnical aspects of care. ${ }^{35}$

We used thoroughness of physical examination as a measure of technical quality of care, and this was the attribute patients valued most. This finding is in line with findings of studies from the United States. ${ }^{21,36}$ Previous discrete choice experiments that have reported that patients give the highest priority to communication and patient-centered care have tended to exclude the assessment of technical care, possibly because of doubts about whether patients can provide a valid assessment. ${ }^{21,36}$ The priority accorded to patient-centered care may reflect patients' assumption of technical quality. When that assumption is challenged, technical quality may become more important. It should be noted that the distinction we made between technical and patient-centered care is not absolute, as communication issues are still relevant in technical care generally and physical examination specifically.

Our data suggest that information provided to patients about practices and physicians to help them make decisions should include information on both technical and interpersonal aspects of care $^{7}$; however, little is known about how patients assess technical care, and patients' assessments may not correlate highly with other objective measures. ${ }^{36}$ Providing information to patients about quality of technical care is challenging, as conventional clinical indexes of quality may not meet the needs of patients. ${ }^{37}$

The value patients placed on seeing a physician who knew them well (relational continuity) was greater on the patient-centered care questionnaire than on the generic questionnaire. Relational continuity might have been expected to be less important when presented in the context of other patient-centered attributes, because both relational continuity and the patient-centered care attributes deal with aspects of the physician-patient relationship. Our results are in line with those of published studies that suggest that continuity is important, ${ }^{38}$ but they extend that work to show that patients still prioritize continuity even when offered a trade with patient-centeredness, which suggests that a reduction in continuity of care could not simply be overcome by professionals with better communication skills. These findings are important given some of the constraints on continuity associated with current health policy. ${ }^{39}$

In conclusion, delivering effective primary care services requires an understanding of patients' priorities. Discrete choice experiments may be criticized for assuming a model of decision making that does not reflect patients' actual judgment processes ${ }^{40}$ and for being highly sensitive to issues of wording and context. ${ }^{19}$ The discrete choice experiment may nevertheless be a useful technique for health services researchers who seek to quantify patients' priorities for primary care services in the context of limited resources.

To read or post commentaries in response to this article, see it online at http://www.annfammed.org/cgi/content/full/6/2/107.

Key words: Priorities; primary care; patient-centered care; office visits; physician-patient relations; quality of care; health services research; health care delivery 
Submitted August 1, 2007; submitted, revised, October 25, 2007; accepted November 14, 2007.

Funding support: This research was conducted by the National Primary Care Research and Development Centre, which received a core grant from the Department of Health, United Kingdom.

Disclaimer: The views expressed in this article are those of the authors

Acknowledgments: We would like to thank the general practices that supported the research and the patients who completed the questionnaires.

\section{References}

1. Laine C, Davidoff F. Patient-centered medicine: a professional evolution. JAMA. 1996;275(2):152-156.

2. Wensing $M$, Jung $H$, Mainz J, Olesen F, Grol R. A systematic review of the literature on patient priorities for general practice care. Part 1: description of the research domain. Soc Sci Med. 1998;47(10):1573-1588.

3. Campbell SM, Roland MO, Buetow SA. Defining quality of care. Soc Sci Med. 2000;51(11):1611-1625.

4. Coulter A. What do patients and the public want from primary care? BMJ. 2005;331(7526):1199-1201.

5. Freeman GK, Olesen F, Hjortdahl P. Continuity of care: an essential element of modern general practice? Fam Pract. 2003;20(6):623-627

6. Bower P, Roland M, Campbell J, Mead N. Setting standards based on patients' views on access and continuity: secondary analysis of data from the general practice assessment survey. BMJ. 2003;326(7383):258

7. Fung $\mathrm{CH}$, Elliott MN, Hays RD, et al. Patients' preferences for technical versus interpersonal quality when selecting a primary care physician. Health Serv Res. 2005;40(4):957-977.

8. Ryan M, Scott D, Reeves $C$, et al. Eliciting public preferences for healthcare: a systematic review of techniques. Health Technol Assess 2001;5(5):1-186.

9. Ryan M, Bate A, Eastmond C, Ludbrook A. Use of discrete choice experiments to elicit preferences. Qual Health Care. 2001;10/Suppl 1):i55-i60.

10. Mead N, Bower P. Patient-centredness: a conceptual framework and review of the empirical literature. Soc Sci Med. 2000;51(7):1087-1110.

11. Little $P$, Everitt $H$, Williamson I, et al. Observational study of effect of patient centredness and positive approach on outcomes of general practice consultations. BMJ. 2001;323(7318):908-911.

12. Mead N, Bower P. Patient-centred consultations and outcomes in primary care: a review of the literature. Patient Educ Couns. 2002;48(1):51-61.

13. Stewart M. Effective physician-patient communication and health outcomes: a review. CMAJ. 1995;152(9):1423-1433.

14. Stewart M, Brown J, Weston W, McWhinney I, McWilliam C, Free man T. Patient-Centred Medicine: Transforming the Clinical Method. London, England: Sage Publications; 1995.

15. Gerard K, Lattimer V. Preferences of patients for emergency services available during usual GP surgery hours: a discrete choice experiment. Fam Pract. 2005;22(1):28-36.

16. Morgan A, Shackley P, Pickin M, Brazier J. Quantifying patient preferences for out of hours primary care. J Health Serv Res Policy. 2000;5(4):214-218.

17. Scott A, Vick S. Patients, doctors and contracts: an application of principal-agent theory to the doctor-patient relationship. Scott J Polit Econ. 1999;46(2):111-134.

18. Vick S, Scott A. Agency in health care. Examining patients' preferences for attributes of the doctor-patient relationship. J Health Econ. 1998;17(5):587-605.
19. Scott A, Watson M, Ross S. Eliciting preferences of the community for out of hours care provided by general practitioners: a stated preference discrete choice experiment. Soc Sci Med. 2003;56(4):803-814.

20. Longo MF, Cohen DR, Hood K, et al. Involving patients in primary care consultations: assessing preferences using discrete choice experiments. Br J Gen Pract. 2006;56(522):35-42.

21. Chapple A, Campbell S, Rogers A, Roland M. Users' understanding of medical knowledge in general practice. Soc Sci Med. 2002;54(8):1215-1224.

22. Markham FW, Diamond JJ, Hermansen CL. The use of conjoint analysis to study patient satisfaction. Eval Health Prof. 1999;22(3):371-378.

23. Ryan M, Gerard K. Using discrete choice experiments to value health care programmes: current practice and future research reflections. Appl Health Econ Health Policy. 2003;2(1):55-64.

24. Cheraghi-Sohi S, Bower P, Mead N, McDonald R, Whalley D, Roland M. What are the key attributes of primary care for patients? Building a conceptual 'map' of patient preferences. Health Expect. 2006;9(3):275-284

25. Ericsson K, Simon H. Protocol Analysis: Verbal Reports as Data. Cambridge, MA: MIT Press; 1984.

26. Cheraghi-Sohi S, Bower P, Mead N, McDonald R, Whalley D, Roland M. Making sense of patient priorities: applying discrete choice methods in primary care using 'think aloud' technique. Fam Pract. 2007;24(3):276-282.

27. Huber J, Zwerina K. The importance of utility balance in efficient choice designs. J Mark Res. 1996;33(Aug):307-311.

28. Carlsson F, Martinsson P. Design techniques for stated preference methods in health economics. Health Econ. 2003;12(4):281-294.

29. Kuhfeld W. Marketing Research Methods in SAS. Cary, NC: SAS Institute Inc; 2005.

30. Hole AR. A comparison of approaches to estimating confidence intervals for willingness to pay measures. Health Econ. 2007;16(8):827-840.

31. Scott A. Identifying and analysing dominant preferences in discrete choice experiments: an application in health care. J Econ Psychol. 2002;23(3):383-398

32. Phillips KA, Johnson FR, Maddala T. Measuring what people value: a comparison of "attitude" and "preference" surveys. Health Serv Res. 2002;37(6):1659-1679.

33. Lancsar E, Louviere J. Deleting 'irrational' responses from discrete choice experiments: a case of investigating or imposing preferences? Health Econ. 2006;15(8):797-811.

34. Coast J, Horrocks S. Developing attributes and levels for discrete choice experiments using qualitative methods. J Health Serv Res Policy. 2007;12(1):25-30.

35. Roland M. The quality and outcomes framework: too early for a final verdict. Br J Gen Pract. 2007;57(540):525-526.

36. Rao M, Clarke A, Hammersley R. Patients' own assessments of quality of primary care compared with objective records based measures of technical quality of care: cross sectional study. BMJ. 2006;333(7557):19-22

37. Marshall M, Noble J, Davies $H$, et al. Development of an information source for patients and the public about general practice services: an action research study. Health Expect. 2006;9(3):265-274.

38. Turner D, Tarrant C, Windridge K, et al. Do patients value continuity of care in general practice? An investigation using stated preference discrete choice experiments. J Health Serv Res Policy. 2007;12(3):132-137.

39. Starfield B, Horder J. Interpersonal continuity: old and new perspectives. Br J Gen Pract. 2007;57(540):527-529.

40. Ryan M, San Miguel F. Revisiting the axiom of completeness in health care. Health Econ. 2004;12(4):295-307. 